\title{
CORPORATE SOCIAL RESPONSIBILITY: EKSPLORASI PERSEPSI, MOTIVASI DAN PRAKTIK
}

\author{
A.A Made Pradnya Darsika ${ }^{1}$ \\ Luh Putu Mahyuni
}

\author{
Universitas Pendidikan Nasional, Bali, Indonesia ${ }^{1,2}$ \\ Email: pradnyadarsika@gmail.com¹ mahyuniluhputu@undiknas.ac.id ${ }^{2}$
}

\begin{abstract}
This study aims to explore the perceptions, motivations and practices of CSR in the hospitality industry. Case study was conducted at Bali Dynasty Resort. To answer research questions, interviews were conducted with important policy makers who have a good understanding of CSR. The data analysis technique was carried out with four steps namely data collection, data reduction, data display and conclusion drawing / verification. In this study, the data validity test uses reference materials, member checks, triangulation of data sources and triangulation of data collection techniques. This study indicates that the perception of management of Bali Dynasty Resort (1) CSR is about how companies manage business processes to produce an overall positive impact on society; (2) CSR refers to the entrepreneur's obligation to make policies and decisions or follow the desired line of action that leads to goals that are in line with community values; (3) CSR is the way the company manages and repairs social and environmental impacts to generate value for shareholders and stakeholders by innovating strategy, organization and operations; (4) CSR is motivated by internal driven or on the basis of social and environmental responsibility; (5) CSR practices based on the philosophy of Tri Hita Karana.
\end{abstract}

Keywords: CSR; Tri Hita Karana; exploration of perception; motivation; practice.

\begin{abstract}
ABSTRAK
Penelitian ini bertujuan untuk mengeksplorasi persepsi, motivasi dan praktik CSR pada industri perhotelan. Studi kasus dilakukan pada Bali Dynasty Resort. Untuk menjawab pertanyaan penelitian, wawancara dilakukan terhadap pengambil kebijakan penting yang memiliki pemahaman yang baik mengenai CSR perusahaan. Teknik analisis data dilakukan dengan empat langkah yaitu data collection, data reduction, data display dan conclusion drawing/verification. Dalam penelitian ini, uji keabsahan data menggunakan bahan refrensi, member check, triangulasi sumber data dan triangulasi teknik pengumpulan data. Penelitian ini mengindikasikan bahwa persepsi management Bali Dynasty Resort (1) CSR adalah tentang bagaimana perusahaan mengelola proses bisnis untuk menghasilkan dampak positif secara keseluruhan kepada masyarakat; (2) CSR mengacu kepada kewajiban pengusaha untuk membuat kebijakan dan keputusan atau mengikuti garis tindakan yang diinginkan yang mengarah pada tujuan yang sesuai dengan nilai-nilai masyarakat; (3) CSR adalah cara perusahaan mengelola dan memperbaiki dampak sosial dan lingkungan untuk menghasilkan nilai bagi pemegang saham dan pemangku kepentingan dengan berinoviasi strategi, organisasi dan operasi; (4) CSR yang dilakukan dimotivasi oleh dorongan internal atau atas dasar tanggung jawab sosial dan lingkungan; (5) Praktik-praktik CSR yang dilakukan berbasis filosofi Tri Hita Karana.
\end{abstract}

Kata Kunci: CSR; Tri Hita Karana; eksplorasi persepsi; motivasi; praktik. 


\section{PENDAHULUAN}

Seiring dengan terjadinya perkembagan pada satu perusahaan akan disusul pula dengan tingginya kesenjangan sosial dan kerusakan lingkungan sebagai akibat dari aktivitas peningkatan laba perusahaan melalui berbagai sumber daya yang dipergunakan oleh perusahaan. Aktivitas operasional perusahaan akan dirasakan pula oleh masyarakat sekitar perusahaan dan lingkungan sekitar perusahaan selain mereka yang memang terlibat langsung di dalam kegiatan perusahaan seperti pelanggan, pemilik atau investor, supplier, komunitas dan juga pesaing (Rosiana dkk., 2013).

Corporate Social Responsibility (CSR) kini banyak dikembangkan oleh perusahaan swasta yang diharapkan akan menjadi investasi perusahaan tersebut dikemudian hari, tidak hanya dianggap sebagai biaya perusahaan (cost). (Sutopoyudo, 2009). Hal ini diatur dalam Undang-Undang Nomor 40 Tahun 2007 Tentang Perseroan Terbatas (UU PT), yang disahkan pada 20 Juli 2007. Pasal 74 Undang-Undang Perseroan Terbatas. Sanksi pidana mengenai pelanggaran CSR pun terdapat didalam Undang Undang Nomor 23 Tahun 1997 tentang Pengelolaan Lingkungan Hidup (UUPLH) Pasal 41 ayat (1) (Hukum Online).

Donaldson dan Preston (1995) dalam stakeholder theory mengatakan bahwa kinerja sebuah organisasi dipengaruhi oleh semua stakeholder organisasi, oleh karena itu merupakan tanggung jawab manajerial untuk memberikan benefit kepada semua stakeholder yang berpengaruh terhadap kinerja organisasi. Menurut Ghozali \& Chariri (2007), Aktivitas suatu perusahaan tidak hanya untuk kepentingan para pemilik saham, namun juga para pemangku kepentingan lain (stakeholder) seperti 
para pemegang saham, kreditor, konsumen, supplier, pemerintah, masyarakat, analis dan pihak lainnya) yang menjadi poin penting dalam stakeholder theory

Menurut Pertiwi \& Unti (2013), disamping berorientasi pada keuntungan (profit), dengan dikembangkannya CRS oleh perusahaan maka kesejahteraan manusia (people) dan keseimbangan alam semesta (planet) jauh lebih diperhatikan juga oleh perusahaan tersebut. Dalam bukunya yang berjudul Cannibal with Forks: The Triple Bottom Line of $21^{\text {st }}$ Century Business oleh John Elkington (1997) menjadikan istilah triple bottom line populer dan dikenal luas.

Rumusan dari konsep ini yaitu disamping profit (laba usaha) dari perusahaan, tindakan nyata yang dilakukan oleh perusahaan untuk lingkungan (planet) dan keadilan (people) akan membuat perushaaan tumbuh dan berkembang serta secara tidak langsung mempengaruhi keberlangsungan dan sustainable development (pembangunan berkelanjutan) pun akhirnya akan tercipta. Beberapa keadaan saling mempengaruhi satu dengan lainnya yang tidak dapat dipisahkan seperti keadaan ekonomi yang bergantung dengan keadaan dari masyarakan dan lingkungan dan keadaan masyarakat dan lingkungan global juga bergantung kepada keadaan ekonomi termasuk didalamnya ekosistem global. Komponen dalam triple bottom line (people, profit, planet) merupakan komponen yang dinamis yang juga tidak stabil namun bergantung dari kondisi dan tekanan seperti tekanan sosial, tekanan politik, tekanan ekonomi, tekanan lingkungan serta konflik kepentingan.

Orientasi terhadap keuntungan (profit oriented), akan menjadikan perusahaan abai terhadap masyarakat sekitar dan berujung pada terjadinya kerusakan terhadap lingkungan sekitar. Tumbuh kembang perusahaan yang 
berkelanjutan, tidak hanya didukung oleh kondisi keuangan saja namun perlu memperhatikan dan memberikan penjaminan terhadap dimensi lain yaitu sosial dan lingkungan hidup sekitar perusahaan. Penghambatan pada bisnis akan terjadi apabila sebuah usaha tidak mampu menjaga keseimbangan dari 3P tersebut. (Pertiwi \& Unti, 2013; Prastowo \& Huda, 2011).

Johnson and Johnson (2006) dalam Hadi (2011) mendefinisikan Corporate Social Responsibility (CSR) is about how companies manage the business processes to produce an overall positive impact on society. Dapat diartikan bahwa tanggung jawab perusahaan (CSR) yaitu tentang bagaimana perusahaan mengatur proses bisnis yang terjadi untuk menghasilkan dampak positif yang secara keseluruhan berdampak kepada masyarakat sekitar. (Lestari \& Indrayani, 2020)

Menurut Susanti \& Mildawari (2014), Corporate Social Responsibility dijadikan perusahaan sebagai suatu pertanggungjawaban sosial mereka terhadap stakeholder dan juga shareholder (pemegang saham). CSR akan menjadikan masyarakat sekitar perusahaan memiliki tingkat perekonomian yang lebih baik yang tentunya akan diikuti oleh kualitas hidup yang mana hal tersebut merupakan salah satu tujuan dari CSR. CSR dapat berfungsi sebagai kompensasi sosial (Sari dkk., 2016). Segala aspek seperti ekonomi, sosial dan lingkungan dari perusahaan akan dapat dipengaruhi dengan adanya pelaksanaan kegiatan CSR. (Untung, 2009; Rosdwianti dkk., 2016).

Pelaksanaan kegiatan CSR dengan suatu budaya memiliki keterkaitan antara satu dengan lainnya. Hal tersebut sesuai dengan hasil penelitian yang dilakukan oleh Wang \& Juslin (2009) yang mana CSR didefinisikan secara berbeda yang 
disebutkan dengan Harmony Approach to CSR (HRCS). Penelitian ini juga melihat bahwa terjadinya peningkatan kinerja dari CSR dengan melakukan pendekatan budaya lokal terhadap kegiatan CSR disamping itu perusahaan juga akan melakukan CSR dengan inisiatif dari internal mereka sendiri serta akan menimbulkan beberapa cara lain yang dapat dilakukan untuk kegiatan CSR

Penelitian ini mencoba mengembangkan pelaksanaan CSR berlandaskan aspek spiritual dan nilai luhur budaya yang dimiliki oleh masyarakat Bali yaitu Tri Hita Karana. Konsep ini menjadi filosofi keseimbangan hidup masyarakat Hindu di Bali yang mana meliputi hubungan yang harmonis antara manusia dengan Tuhan (parhyangan), antar sesama manusia (pawongan), dan antara manusia dengan lingkungan (palemahan).

Hasil penelitian yang dilakukan oleh Rustiarini (2010) menyebutkan bahwa perusahaan yang memiliki kinerja sosial dan lingkungan yang baik, maka akan diikuti secara positif dengan adanya peningkatan harga saham dan munculnya kepercayaan dari para investor terhadap perusahaan tersebut. Mengingat adanya pendekatan budaya lokal yaitu Tri Hita Karana yang dilakukan oleh beberapa perusahaan dalam melakukan praktik-praktik CSR di Bali, maka akan menjadi suatu daya tarik yang unik untuk meyakinkan para investor untuk dapat melakukan investasi di Bali yang akan berujung pada membaiknya kinerja keuangan dari suatu perusahaan.

Implementation of CSR program on hotel industry gives benefit for the hotel, by applying CSR activity provides positive impact that earned in a long period of time. Even tough hotel industry do not sell any natural resources like mining in 
general, however hotel industry also uses natural resources such as water to run its business. As for some of the positive impacts for hospitality companies to carry out CSR include: gaining trust in the surrounding community, building the company's reputation, improving relationships with regulators and stakeholders, sustainable condition, and if done in Bali, will get the opportunity to get awards such as the Tri Hita Karana Award. (Bithara, Widiana dan Murni, 2020)

Menurut Wiana (2004) menyatakan bahwa Tri Hita Karana merupakan falsafah hidup tangguh. Falsafah tersebut memiliki konsep yang dapat melestarikan keanekaragaman budaya dan lingkungan ditengah hantaman globalisasi dan homogenisasi. Teori keseimbangan antara diri sendiri dan lingkungan ditekankan pada falsafah ini. Umat Hindu di Bali meyakini bahwa keseimbangan tersebut akan terbentuk dalam satu prilaku yang dilakukan oleh masyarakat melalui beberapa hubungan yang sering disebut dengan parhyangan, pawongan dan palemahan.

Ketiga unsur tersebut yaitu (parahyangan) hubungan manusia dengan Tuhan. (pawongan) hubungan manusia dengan sesama manusia dan (palemahan) hubungan manusia dengan lingkungan. Parhyangan lebih menekankan agar manusia menjaga kebersihan dan kesucian dirinya secara lahir dan batin serta selalu mendekatkan diri pada Tuhan. Pawongan melandasi rasa kasih sayang, saling menolong dan toleransi. Palemahan menekankan pada kemampuan manusia untuk memelihara, menjaga dan memperbaiki kualitas lingkungannya melalui serangkaian upacara tertentu (Pramesti,2019).

Salah satu penghargaan atau akreditasi yang berkaitan dengan kegiatan Tri Hita Karana yang ada di Bali yang dilakukan oleh Yayasan Tri Hita Karana Bali 
yaitu Tri Hita Karana Award and Accreditations untuk beberapa sektor usaha seperti perhotelan, bank, koperasi, lembaga pendidikan dan lembaga lainnya dapat mengikuti akreditasi tersebut.

Salah satu hotel di Bali yang sudah mendapatkan anugrah Tri Hita Karana Award yaitu Bali Dynasty Resort dan penghargaan yang diperoleh yaitu Platinum IV yang memiliki arti bahwa Bali Dynasty Resort sudah mampu membuat dan mempertahankan suatu hubungan yang harmonis antara manusia dengan lingkungan (palemahan), antara sesama (pawongan) dan tentu saja dengan Sang Pencipta (parhyangan) yang menjadi inti dari penilaian Tri Hita Karana Award.

Penelitian ini dilakukan untuk mengetahui persepsi management mengenai CSR, motivasi dari perusahaan dalam melakukan CSR dan bagaimana perusahaan mengimplementasikan praktik-praktik dan juga menyelaraskan kegiatan CSR dengan kebutuhan saat ini yang berkaitan dengan lingkungan, masyarakat dan Tuhan Yang Maha Esa atau berbasis pada filosofi Tri Hita Karana.

Adapun pertanyaan yang timbul yaitu (1) Bagaimana persepsi dari

management Bali Dynasty Resort terhadap CSR?; (2) Apa motivasi dari Bali Dynasty Resort dalam melaksanakan kegiatan CSR?; (3) Bagaimanakah implementasi praktik-praktik CSR berlandaskan filosofi Tri Hita Karana yang dilaksanakan di Bali Dynasty Resort?

\section{METODE PENELITIAN}

Penelitian ini dilakukan pada periode Januari sampai dengan Juni 2020 di Bali Dynasty Resort. Untuk menjawab pertanyaan penelitian, wawancara 
mendalam dilakukan terhadap beberapa informan yang dianggap mengetahui, terlibat dan berperan di dalam dan mengetahui proses dari Corporate Social Responsibility (CSR) yang berbasis Tri Hita Karana di Bali Dynasty Resort. Terdapat beberapa pertanyaan yang diajukan diantaranya: 1. Apakah yang dimaksud dengan CSR?; 2. Apa motivasi untuk melakukan CSR; 3. Praktik CSR apa yang sudah dilakukan di Bali Dynasty Resort yang berbasi Tri Hita Karana (parhyangan, pawongan dan palemahan). Wawancara dilakukan dengan durasi rata-rata 30 menit. Wawancara direkam dengan perekam audio atas seijin partisipan. Setelah data yang diperoleh oleh peneliti melalui berbagai proses diantaranya proses wawancara, studi dokumentasi dan observasi, maka peneliti akan melakukan penyajian data. Data yang diperoleh melalui proses wawancara dan observasi, akan dituangkan kedalam teks (transkrip wawancara) yang nantinya dikelompokkan ke dalam coding dan theming sesuai dengan fokus permasalahan pada penelitian ini.

Teknik analisis data dalam penelitian ini, akan dilakukan dengan empat langkah yaitu: data collection, data reduction, data display dan conclusion drawing/verification. Uji keabsahaan data pada penelitian ini menggunakan bahan refrensi, member check, triangulasi sumber data dan triangulasi teknik pengumpulan data. (Sugiyono, 2017). Untuk menjaga prinsip anonimitas, penulis memberikan kode khusus kepada informan yaitu kode HRM untuk Human Resources Manager Bali Dynasty Resort, kode SM untuk Sales Manager Bali Dynasty Resort, kode KL untuk Kepala Lingkungan Banjar Segara Kuta dan kode WS untuk Warga Sekitar yang bekerja di Bali Dynasty Resort. Sehingga setiap 
kutipan yang dipaparkan dalam pemaparan hasil diakhiri dengan kode partisipan yang menyatakan pernyataan tertentu.

\section{HASIL DAN PEMBAHASAN}

Analisis menunjukkan bahwa seluruh informan yang diwawancarai memiliki persepsi yang dalam mengenai CSR dan Tri Hita Karana yang dilakukan di Bali Dynasty Resort. Sejalan dengan hal tersebut penelitian ini memberikan gambaran mengenai persepsi mengenai CSR, motivasi dalam melakukan CSR dan implementasi praktik-praktik CSR berbasis Tri Hita Karana di Bali Dynasty Resort. Berikut adalah penjelasan lebih lanjut untuk masing-masing implementasi praktikpraktik CSR berbasis filosofi Tri Hita Karana.

Persepsi Management Bali Dynasty Resort terhadap CSR. Secara umum terdapat empat kode utama yang dipergunakan untuk mengetahui pemahaman management Bali Dynasty Resort terhadap CSR yaitu: 1. CSR adalah tentang bagaimana perusahaan mengelola proses bisnis untuk menghasilkan dampak positif secara keseluruhan kepada masyarakat; 2. CSR mengacu kepada kewajiban pengusaha untuk membuat kebijakan dan keputusan atau mengikuti garis tindakan yang diinginkan yang mengarah pada tujuan yang sesuai dengan nilai-nilai masyarakat; 3. CSR adalah cara perusahaan mengelola dan memperbaiki dampak sosial dan lingkungan untuk menghasilkan nilai bagi pemegang saham dan pemangku kepentingan dengan berinoviasi strategi, organisasi dan operasi; 4. Tanggung jawab sosial adalah tentang merawat orang. Hal ini berlaku untuk karyawan dan orang-orang yang membutuhkan kesehatan kami layani. 
Peneliti hanya mengambil sudut pandang dari management Bali Dynasty Resort mengenai persepsi mereka terhadap CSR yang mana diuraikan sebagai berikut: CSR adalah tentang bagaimana perusahaan mengelola proses bisnis untuk menghasilkan dampak positif secara keseluruhan kepada masyarakat. Management Bali Dynasty Resort memiliki pemahaman dimana CSR adalah tentang bagaimana perusahaan mengelola proses bisnis untuk menghasilkan dampak positif secara keseluruhan kepada masyarakat. Hal tersebut disampaikan oleh SM “...baik itu dari lingkungan hidupnya apa tempatnya dia berada yaitu berada di posisi pantai, menjaga lingkungan di daerah sana, kemudian gimana tanggung jawabnya kita terhadap masyarakat yang berada diseputaran itu dan itu memang tujuannya gimana sih menunjukkan kontribusi itu kontribusi perusahaan itu sendiri ke faktor-faktor eksternal yang ada disekitarnya.". Disamping itu pendapat yang sama ditambahkan oleh HRM “Habis itu Desa Adat itu punya apa. Punya program apa. Kalau misalnya kita bisa support...". Dalam hal ini masyarakat sekitar yang dimaksud oleh management adalah dari Desa Adat Kuta yang memang menaungi Bali Dynasty Resort dan secara khusus Banjar Segara Kuta yang selama ini menjadi stakeholder langsung dari Bali Dynasty Resort.

CSR mengacu kepada kewajiban pengusaha untuk membuat kebijakan dan keputusan atau mengikuti garis tindakan yang diinginkan yang mengarah pada tujuan yang sesuai dengan nilai-nilai masyarakat. Tambahan pemahaman mengenai CSR yang mengacu kepada kewajiban pengusaha untuk membuat kebijakan dan keputusan atau mengikuti garis tindakan yang diinginkan yang mengarah pada tujuan yang sesuai dengan nilai-nilai masyarakat dinyatakan dengan pernyataan 
dari HRM “CSR untuk hotel itu yang tepat guna dong, CSR klo seumpamanya gini umpamanya kita lokasi hotel di Kuta Badung trus kita CSRnya ngasi beras. Itu sebenarnya tidak membantu. Yang justru sebenarnya kita terapkan adalah menampung mereka misalnya mereka punya anak sekolah trainee maksimalkan mereka misalnya sekolahnya dimana, klo dia trainee umpamanya dia tinggal di Kuta, nah kita bisa take care itu sampai lulus. Kalau semisalnya lulus itu, kan nanti kita bisa regenerasikan nanti mereka bisa menjadi tenaga kerja kita. Itu salah satunya."

CSR adalah cara perusahaan mengelola dan memperbaiki dampak sosial dan lingkungan untuk menghasilkan nilai bagi pemegang saham dan pemangku kepentingan dengan berinoviasi strategi, organisasi dan operasi. Selain itu Corporate Social Responsibility adalah cara perusahaan mengelola dan memperbaiki dampak sosial dan lingkungan untuk menghasilkan nilai bagi pemegang saham dan pemangku kepentingan dengan berinoviasi strategi, organisasi dan operasi. Hal ini disampaikan oleh SM "Jadi untuk SM sendiri sih, Corporate Social Responsibility itu lebih ke tanggung jawab perusahaan terhadap lingkungan sekitarnya,"

Motivasi dalam Melakukan Kegiatan CSR di Bali Dynasty Resort. Motivasi ataupun yang menjadi alasan dalam melakukan CSR secara umum dapat dikelompokkan menjadi tiga yaitu didorong oleh tanggung jawab sosial dan lingkungan, trend atau penghargaan dan kepentingan sosial atau citra dari perusahaan. 
Motivasi dalam kegiatan CSR berdasarkan tanggung jawab sosial dan lingkungan. Motivasi dalam melakukan kegiatan CSR di Bali Dynasty Resort berdasarkan tanggung jawab sosial dan lingkungan disampaikan oleh informan dalam penelitian ini sebagaimana dipaparkan oleh HRM "...nanti akan kembali ke kesejahteraan hotel itu sendiri yang bisa men-support hotel itu sendiri.” “.. pada saat ada hotel star rating, ada audit dari lingkungan ditanya pembuangan sampah sama siapa dengan siapa. Semuanya. Kalau kalian bisa sama seperti Asri Karya, ga masalah. Kita pasti support." Tambah HRM. Penjelasan didukung oleh SM “...akan menjalin kerja sama yang baik apa bila kita melakukan CSR nya dengan baik."

Pemaparan lebih jauh mengenai motivasi melakukan kegiatan CSR berdasarkan tanggung jawab sosial dan lingkungan juga disampaikan oleh KL “...kita juga membantu apa namanya menjaga kebersihan lingkungan. Kita ajak juga kerja sama mereka semua ikut bergabung dengan kita" Kkita sudah memohon untuk kerja sama sampah tapi mereka masih pending ya" imbuh KL. WS juga menyampaikan pernyataan "Lebih sering kepedulian terhadap siapa saja yang ada disekitar hotel. kegiatannya positif dan bisa saling membantu ya bagus, cocok diteruskan"

Motivasi dalam kegiatan CSR berdasarkan trend atau penghargaan. Motivasi lain dalam melakukan kegiatan CSR di Bali Dynasty Resort berdasarkan trend atau penghargaan disampaikan oleh SM "...karena mungkin kegiatan CSR yang dilakukanpun sudah dan selalu berkaitan dengan Tri Hita Karana." 
Motivasai dalam kegiatan CSR berdasarkan kepentingan sosial atau citra. Motivasi selanjutnya untuk melakukan kegiatan CSR yaitu berdasarkan kepentingan sosial atau citra perusahaan. Pernyataan disampaikan oleh informan "..juga masih bertahan dan dapat image yang bagus ya diluaran sana dari kegiatankegiatan itu tentunya juga." (WS). Selanjutnya ditambahkan pernyataan pendukung "Mungkin lebih ke image baik ya dimanapun perusahan itu baik di lingkungan sekitar, pemerintah dan para tamu." (SM). Lebih lanjut dinyatakan oleh HRM "Owner dari sisi owner juga malah. Intinya saya tidak mau ada publicity yang negatif. Yang negatif yang malu-maluin katanya.”

Implementasi Praktik-Praktik CSR Berbasis Tri Hita Karana di Bali Dynasty Resort. Implementasi praktik-praktik CSR berbasis filosofi Tri Hita Karana di Bali Dynasty Resort dibagi kedalam tiga praktik yaitu praktik CSR berbasis parhyangan, CSR berbasis pawongan dan CSR berbasis palemahan. Implementasi praktik CSR berbasis parhyangan. Implementasi praktik-praktik CSR berbasis parhyangan (hubungan antara manusia dengan Tuhan) disampaikan oleh informan HRM "CSR ini juga diluar ini ya berbasis Tri Hita Karana. Kita support programnya dari pawongan, parhyangan, palemahan. Kayak kemarin kita THK itu yang di Batukaru. Sekalian tim Hindunya nyumbang tempat sampah seperti itu..." Tambahan informasi praktik-praktik parhyangan juga disampaikan oleh SM “...contohnya setiap ada pura di hotel, kita kan selalu ada odalan, nah itu kita selalu rutin melaksanakannya." Pernyataan tersebut didukung oleh WS "Piodalan ring Pura hotel nike rutin, tiang juga maturan biasanya. Pake gong juga sama pedanda biasanya." 
A.A Made Pradnya Darsika dan Luh Putu Mahyuni. Corporate Social Responsibility: Eksplorasi...

Implementasi praktik CSR berbasis pawongan. Praktik-praktik CSR berbasis pawongan (hubungan yang harmonis antar sesama) dinyatakan oleh SM "Bali Dynasty ada bekerja sama dengan salah satu lembaga CSR yang kita membuat rumah singgah untuk orang-orang yang memiliki keluarga yang sakit tapi tidak ada tempat tinggal jadi kita menyediakan tempat tinggal untuk yang orangorang yang belum mampu selama mereka dalam masa perawatan di Rumah Sakit." Pernyataan ini didukung oleh WS "Yang tiang tau juga mangkin kan punya program juga sareng Solemen, wenten boneka yang dijual juga disini, jadi anakanak bule biasanya ada juga yang beli beberapa dan hasilnya nike disumbangkan untuk Solemen. Sebelumnya yang di Karangasem, mereka juga diberikan bantuan secara rutin dari hotel. Sampai wenten sane lanjut sekolah."

Pendapat tersebut didukung oleh HRM "yang disekolahkan itu adalah masyarakat sekitar Desa Cegi itu, mereka tidak membayar sekolah sampai terakhir kemarin sampai lulus ada yang sampai kuliah di Undiksa. Kadang-kadang yang repeater itu sampe bawa 1 koper. This is for Solemen." WS menambahkan "Sebelumnya nike wenten program yang kerja sama kerja sama sama yang di Karangasem. Mereka dibantu drike. Wenten sane ngaryanin tempat sampah, lalu dibawa ke hotel untuk diletakkan dikamar, Kan men-support nggih nike kerajinan dan penghijauan juga." Sementara itu pendapat lain mengenai praktik-praktik CSR berbasis pawongan disampaikan oleh KL "Kita sudah bekerja sama dengan seluruh hotel yang ada di Lingkungan Segara ini, membantu lansia."

Implementasi praktik CSR berbasis palemahan. Implementasi praktikpraktik Corporate Social Responsibility berbasis palemahan (hubungan harmonis 
antara manusia dengan lingkungan) dinyatakan dalam pernyataan oleh KL “...melakukan general cleaning atau beach cleaning. Pengelolaannya adalah Desa Adat. Desa Adat melalui team-nya membersihkan di pantai." Pendapat ini didukung oleh pendapat dari WS “...sering mengadakan bersih-bersih lingkungan, dipantai, banyak yang ikut juga." dan “....kita selalu rutin mengadakan dan juga turut serta dalam beach cleaning seperti itu." Pendapat lain mengenai praktik-praktik Corporate Social Responsibility berbasis palemahan disampaikan oleh HRM “...mulai dari tahun 2000, waktu itu kita bekerja sama dengan Bali Povety di Cegi Karangasem. Terus untuk yang bambunya, mereka membuat tempat sampah anyaman dari bambu terus kita pakai dikamar-kamar waktu itu."

Penelitian ini mengindikasikan bahwa management dari Bali Dynasty Resort memiliki persepsi terhadap Corporate Social Responsibility adalah tentang bagaimana perusahaan mengelola proses bisnis untuk menghasilkan dampak positif secara keseluruhan kepada masyarakat yang dapat dilihat bahwa mereka selalu mendukung segala kegiatan yang dilakukan oleh lingkungan Banjar Segara Kuta ataupun Desa Adat Kuta dan masyarakat sekitar.

Selain itu Corporate Social Responsibility juga dipandang harus mengacu kepada kewajiban pengusaha untuk membuat kebijakan dan keputusan atau mengikuti garis tindakan yang diinginkan yang mengarah pada tujuan yang sesuai dengan nilai-nilai masyarakat yang terbukti dari CSR yang dijalankan haruslah yang tepat guna kepada yang dituju serta tetap menjaga tujuan bisnis yang dijalani.

Persepsi lainnya juga melihat Corporate Social Responsibility merupakan suatu cara perusahaan mengelola dan memperbaiki dampak sosial dan lingkungan 
untuk menghasilkan nilai bagi pemegang saham dan pemangku kepentingan dengan berinoviasi strategi, organisasi dan operasi yang dalam hal ini terlihat dimana mereka berupaya untuk selalu menjaga lingkungan sekitar agar tetap layak untuk dinikmati oleh wisatawan yang menginap di Bali Dynasty Resort. Semua pemahaman mengenai CSR tersebut sesuai dengan teori mengenai CSR yang disampaikan oleh Totok (2018).

Disamping trend/ penghargaan dan kepentingan sosial/ citra, CSR yang dilakukan di Bali Dynasty Resort lebih didasari pada tanggung jawab sosial dan lingkungan yang berarti bahwa motivasi dari Bali Dynasty Resort dalam menjalankan kegiatan CSR berasal dari dalam (internal driven) yang mengindikasikan bahwa CSR dilakukan untuk menciptakan keselarasan harmonisasi berdasarkan filosofi Tri Hita Karana (harmonisasi antara manusia dengan Tuhan, harmonisasi antara sesama manusia dan harmonisasi antara manusia dengan lingkungan)

Penguatan informasi ini diperoleh juga dari pendapat stakeholder mengenai motivasi Bali Dynasty Resort dalam melakukan CSR memang didorong oleh keinginan dari dalam atau internal driven atau atas dasar tanggung jawab sosial dan lingkungan. Keberadaan CSR sebagai dasar dari tanggung jawab sosial dan lingkungan juga dapat diartikan sebagai sarana untuk mencegah konflik yang sedang terjadi yang mana dalam penelitian ini terlihat dari adanya keinginan dari Banjar Segara Kuta untuk mengelola sampah dari Bali Dynasty Resort sementara Bali Dynasty Resort masih menggunakan pihak lain (Asri Karya) dan menunggu kelengkapan ijin yang dimiliki oleh pengelola sampah dari Banjar Segara Kuta. 
Hasil penelitian ini menguatkan hasil penelitian sebelumnya yang mengindikasikan bahwa kesadaran dalam melakukan CSR memang didasari dari dalam perusahaan (internal driven). Internal driven akan membuat kegiatan jauh lebih ringan mengingat tidak adanya keterpaksaan dalam melakukan suatu kegiatan khususnya CSR pada suatu perusahaan karena didasari oleh keinginan yang tulus ikhlas (Dianti \& Mahyuni, 2018)

Dalam hal implementasi praktik-praktik CSR berbasis filosofi Tri Hita Karana, Bali Dynasty Resort sudah menjalankan semua praktik-praktik tersebut baik itu dari praktik CSR berbasis parhyangan, praktik CSR berbasis pawongan dan praktik CSR berbasis palemahan. Praktik CSR yang dilakukan secara rutin dan berkelanjutan. Beberapa kegiatan CSR juga dilakukan dengan bekerja sama dengan beberapa pihak ketiga (third party) seperti bekerja sama dengan Bali Povety dan Solemen. Bali Dynasty Resort tentunya menjalin dan bekerja sama juga dengan Banjar Segara Kuta dalam menjalankan beberapa program-program CSR mereka mengingat hotel ini berada di wilayah Banjar Segara Kuta.

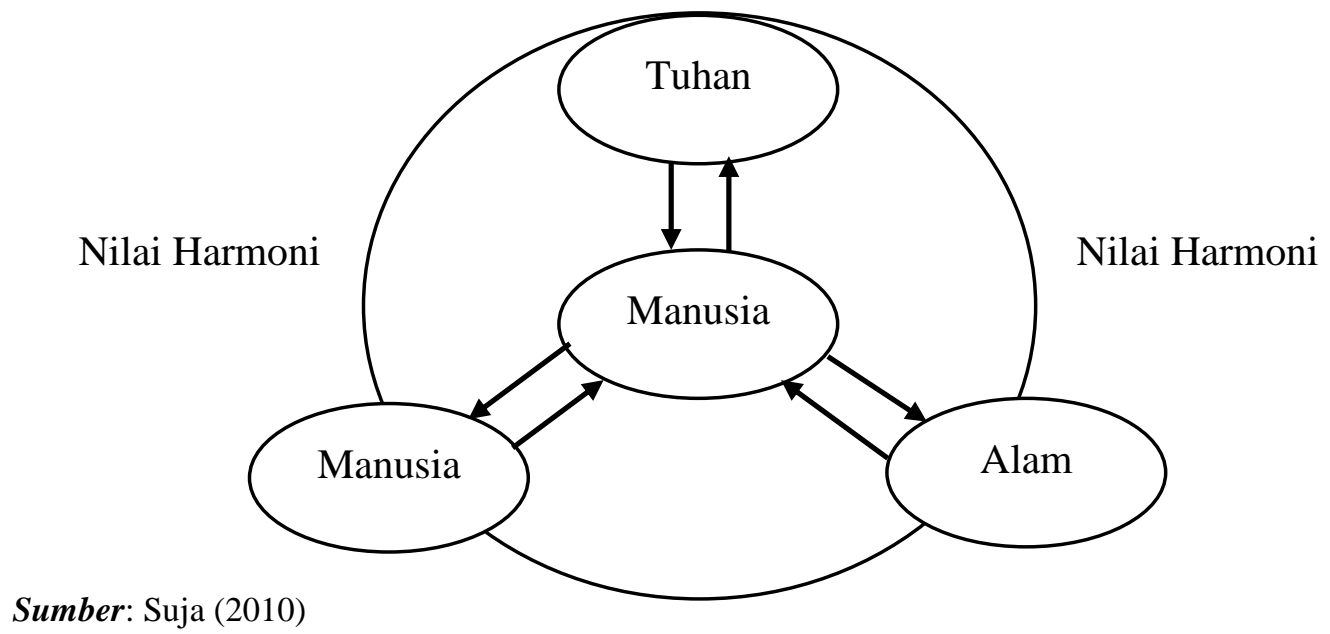




\section{Gambar 1. \\ Pendekatan Kebudayaan Tri Hita Karana}

CSR berbasis parhyangan diterapkan dengan melakukan giat bersih di salah satu pura di Bali dan sekaligus menyumbangkan tempat sampah yang dikordinir oleh Sie Hindu Bali Dynasty Resort. Penelitian CSR berbasis pawongan yang dilakukan di Bali Dynasty Resort kegiatannya lebih beragam diantaranya mengadakan kerja sama dengan third party (Solemen) untuk menyediakan rumah singgah, menyekolahkan beberapa penduduk di Desa Cegi Karangasem hingga perguruan tinggi dan juga membantu lansia di Lingkungan Banjar Segara disamping secara rutin mengadakan kegiatan donor darah. CSR berbasis palemahan yang dilakukan di Bali Dynasty Resort juga beragam diantaranya mengelola pohon bambu yang ada di Desa Cegi untuk dijadikan tempat sampah dan anyaman yang kemudian di display di kamar-kamar, mengadakan kegiatan penghijauan dan kegiatan bersih-bersih pantai dan lingkungan sekitar dimana juga tetap bekerja sama dengan Desa Adat Kuta dan Lingkungan Banjar Segara.

Dalam melaksanakan program CSR berdasarkan kearifan lokal, maka perusahaan perlu memahami kebutuhan masyarakat dari perspektif masyarakat setempat. Komunikasi dua arah (two ways communication) yang dijalin antara perusahaan dan masyarakat lokal sangat penting dan membangun hubungan dengan tokoh-tokoh masyarakat setempat. (Rosilawati \& Krisna, 2019)

\section{SIMPULAN DAN SARAN}

Penelitian ini menemukan bahwa management Bali Dynasty Resort sudah memiliki pemahaman yang baik mengenai Corporate Social Responsibility (CSR) 
dimana mereka menganggap CSR lebih kepada dampak positif yang diberikan kepada lingkungan dan masyarakat sekitar. CSR juga dijadikan sebagai dasar dalam membuat kebijakan dan keputusan yang sesuai dengan nilai-nilai yang dikandung di dalam masyarakat. Pemahaman lainnya yaitu CSR dianggap sebagai salah satu cara perusahaan untuk mengelola dan memperbaiki dampak sosial dan lingkungan yang juga akan berdampak kepada para pemilik saham dan pemangku kepentingan.

Penelitian ini menemukan juga bahwa motivasi untuk melakukan CSR di Bali Dynasty Resort yaitu berasal dari dorongan internal perusahaan atau internal driven yang membuat CSR yang dilakukan tidak lagi bertujuan untuk mengumpulkan profit atau keuntungan bagi perusahaan atau demi kepentingan bisnis melainkan merupakan suatu tanggung jawab sosial dan lingkungan. Perspektif ini perlu selalu dijadikan dasar yang baik dalam melakukan kegiatan CSR untuk semua perusahaan tidak hanya perhotelan. Keberhasilan program CSR di Bali Dynasty Resort juga dapat dilihat dari antusias para tamu yang menginap disana untuk ikut membantu program-program CSR yang dijalankan di Bali Dynasty Resort termasuk mereka yang menjadi repeater. Hal ini juga nantinya diharapkan dapat menumbuhkan loyalitas terhadap tamu di Bali Dynasty Resort.

Penelitian ini telah berupaya untuk melihat CSR sebagai suatu yang dapat menyelesaikan ketegangan antar pihak ataupun perselisihan. Pada penelitian ini ketegangan antar pihak dapat dilihat dari keinginan Banjar Segara Kuta untuk mengelola sampah di Bali Dynasty Resort sementara itu dari pihak Bali Dynasty Resort meminta untuk melengkapi ijin-ijin yang semestinya dimiliki dan diurus oleh Banjar Segara Kuta. Namun Banjar Segara Kuta memberikan kurun waktu 
selama dua tahun agar nantinya semua perusahaan baik itu hotel, villa, restaurant yang berada di bawah pengawasan Banjar Segara Kuta untuk bergabung dan memberikan ruang kepada mereka dalam pengelolaan sampah.

Implementasi praktik-praktik CSR yang dilakukan selama ini di Bali Dynasty Resort sudah berbasis pada filosofi Tri Hita Karana dimana mereka mampu melakukan kegiatan CSR berbasis parhyangan, pawongan dan palemahan secara berkesinambungan. Penelitian ini juga menemukan bahwa program CSR berbasis pawongan dan berbasis palemahan memiliki porsi yang lebih sering dilakukan dari pada parhyangan. Sehingga kedepannya Bali Dynasty Resort agar dapat lebih adil dalam menjalankan kegiatan CSR berbasis filosofi Tri Hita Karana.

Akan tetapi, penelitian ini hanya difokuskan pada implementasi praktikpraktik CSR berbasis filosofi Tri Hita Karana, mungkin temuan dalam penelitian ini kurang relevan dengan daerah di luar Bali yang memiliki kearifan lokal lain. Adapun penelitian selanjutnya diharapkan mengungkap praktik-praktik CSR berbasis kearifan lokal lainnya dan juga lebih melihat CSR sebagai salah satu cara dalam mengatasi konflik yang terjadi antara para pihak.

\section{REFERENSI}

Birthara, B., Arta, W., \& Suci, M. (2020). Implementing Tri Hita Karana Values in Grand Inna Kuta's Corporate Social Responsibility Program. International Journal of Green Tourism Research and Applications, 2.(1): 1-10.

Dianti, G., \& Mahyuni, L. (2018). Praktik Corporate Social Responsibility (CSR) Pada InterContinental Bali Resort: Eksplorasi Berbasis Pendekatan Filosofi Tri Hita Karana. Jurnal Ilmiah Akuntansi \& Bisnis Volume 3, No. 1, 12-22.

Donaldson, T., \& Preston, L. E. (1995). The Stakeholder Theory of The Corporation: Concepts,Evidence and Implications. Academy of Management Review, 20 (1), 65-91. 
Elkington, J. (1998). Cannibals With Forks: The Triple Bottom Line in 21 st Century Business. London: Oxford.

Ghozali, I., \& Chariri, A. (2007). Teori Akuntansi Edisi Ketiga. Semarang: BPFE.

Hadi, N. (2011). Corporate Social Responsibility. Yogyakarta: Graha Ilmu.

Hukum, O. (1997, September 16). hukumonline.com. Retrieved from https://www.hukumonline.com/: https://www.hukumonline.com/

Hukum, O. (2007, Agustus 16). hukumonline.com. Retrieved from https://www.hukumonline.com/: https://www.hukumonline.com

Lestari, N. L., \& Vita, I. (2020). Corporate Social Responsibility Tri Hita Karana Dalam Sustainibilitas Perusahaan (Filosofi dan Implementasi). Jurnal Riset Akuntansi JUARA, 10.(1): 37-46.

Mardikanto, T. (2018). Corporate Social Responsibility Tanggung Jawab Sosial Korporasi. Bandung: Alfabeta.

Pertiwi, E., \& Unti, L. (2013). Implementasi Corporate Social Responsibility Berlandaskan Tri Hita Karana. Jurnal Akuntansi Multiparadigma, 4.(3): 330-507.

Pramesti, D. S. (2019). Implementasi Konsep Tri Hita Karana Pada Akomodasi Pariwisata Di Nusa Dua, Bali (Study Kasus: Melia Bali Villas and Spa Resort). JOURNEY Volume 1 Nomor 1, 207-228.

Prastowo, J., \& dan M, H. (2011). Corporate Social Responsibility: Kunci Meraih Kemuliaan Bisnis. Yogyakarta: Samudra Biru.

Rosdwianti, M. K., Dzulkirom, M., \& Zahroh, Z. A. (2016). Pengaruh Corporate Social Responsibility ( Csr ) Terhadap Profitabilitas Perusahaan ( Studi Pada Sektor Industri Barang Konsumsi Yang Terdaftar Di Bursa Efek Indonesia Periode 2013-2014 ). Jurnal Administrasi Bisnis (JAB) Vol. 38 No.2, 16-22.

Rosiana, E., Juliarsa, G., \& M, M. (2013). Pengaruh Pengungkapan CSR Terhadap Nilai Perusahaan Dengan Profitabilitas Sebagai Variabel Pemoderasi. EJurnal Akuntansi Universitas Udayana 5.3, 723-738.

Rosilawati, Y., \& Mulawarman, K. (2019). Kearifan Lokal Tri Hita Karana Dalam Program Corporate Social Responsibility. Jurnal ASPIKOM, 3.(6): 1215-1227. 
Rustiarini, N. (2010). Pengaruh Corporate Governance pada Hubungan Corporate Social Responsibility dan Nilai Perusahaan. Prosiding Simposium Nasional Akuntansi XIII Purwokerto 2010 (pp. 1-24). Surakarta: Prosiding Simposium Nasional Akuntansi XIII Purwokerto 2010.

Sari, W., Siti, L., \& Nila, F. (2016). Pengaruh Pengungkapan Corporate Social Responsibility Terhadap Kinerja Keuangan Dan Nilai Perusahaan (Studi Komparatif pada Perusahaan Multinasional yang Terdaftar di Bursa Efek Indonesia dan Bursa Malaysia Tahun 2012-2015). Jurnal Administrasi Bisnis Universitas Brawijaya. Vol. 39. No. 2., 74-83.

Sugiyono. (2017). Memahami Penelitian Kualitatif. Bandung: Alfabeta.

Suja, I. W. (2010). Kearifan Lokal Sains Asli Bali. Surabaya: Paramita.

Susanti, R., \& Mildawari, T. (2014). Pengaruh Kepemilikan Manajemen, Kepemilikan Institusional Dan Corporate Social Responsibility. Jurnal Ilmu dan Riset Akuntansi STIESIA. Vol. 3. No. 1, 1-18.

Sutopoyudo. (2009, September 21). Sutopoyudo Wordpress. Retrieved from https://sutopoyudo.wordpress.com/: https://sutopoyudo.wordpress.com/

Untung, B. (2009). Corporate Social Responsibility. Jakarta: Sinar Grafika.

Wang, L., \& H, J. (2009). The Impact of Chinese Culture on Corporate Social Responsibility: The Harmony Approach. Journal of Business Ethics (2009) 88, 433-451.

Wiana, I. K. (2004). Tri Hita Karana Menurut Konsep Hindu. Surabaya: Paramita. 